\title{
Perancangan Motion Graphic Science Show 2020 Tentang Pengenalan Spesies Baru
}

\author{
Kingsley Valentino ${ }^{1}$, Julius Andi Nugroho², Budi Darmo 3 \\ 123 Desain Komunikasi Visual, Fakultas Seni Rupa dan Desain, Universitas Tarumanagara, Jakarta \\ kingsley.625170045@stu.untar.ac.id, juliusn@fsrd.untar.ac.id, budid@fsrd.untar.ac.id
}

\begin{abstract}
Abstrak - Setiap tahun LIPI (Lembaga IImu Pengetahuan Indonesia) mengadakan acara Science Show dalam Indonesia Science Expo yang bertujuan untuk mengedukasi masyarakat tentang sains. Untuk tahun 2020 ini, temanya adalah "bagaimana cara mengenali spesies baru", yang didalamnya akan dijelaskan tentang penemuan apa saja yang sudah ditemukan pada tahun ini dan bagaimana cara mengidentifikasi spesies tersebut. Namun dikarenakan pandemi Covid-19, acara ini diubah menjadi online. Sehingga metode presentasi materi yang biasa digunakan pun juga berubah, dari tatap muka yang dijelaskan oleh Peneliti LIPI diubah menjadi video motion grafis agar menarik dan tidak membosankan. Tujuan dari perancangan ini bagaimana merancang video motion graphic Science Show 2020 tentang pengenalan spesies baru. Video motion graphic ini bertujuan untuk mengedukasi pelajar SMA ditengah pandemi ini. Penulis menggunakan beberapa metode yaitu; observasi, wawancara, studi pustaka, dan kuesioner. Metode perancangan terdiri dari pra produksi, produksi dan pasca produksi. Hasil dari Perancangan ini adalah video motion graphic tentang pengenalan spesies baru yang sederhana dan modern. Video motion graphic ini juga mengggunakan model karakter animasi peneliti LIPI yang menerangkan tentang spesies baru dan bagaimana cara mengenalinya. Video dengan durasi 5-6 menit ini menggunakan full HD dan memiliki tone visual yang disukai oleh pelajar SMA. Video motion graphic nantinya akan ditaruh di kanal Youtube LIPI.
\end{abstract}

Kata kunci: Perancangan video; Sains; Spesies baru; Video Motion Graphic

\section{PENDAHULUAN}

Setiap tahunnya LIPI (Lembaga IImu Pengetahuan Indonesia) mengadakan acara yang bernama Indonesia Science Expo. Dari wawancara yang dilakukan penulis dengan pihak LIPI ternyata pada Indonesia Science Expo tersebut di dalamnya terdapat banyak acara dan kegiatan yang dilaksanakan secara tatap muka. Salah satu acara besar yang diusung dalam Indonesia Science Expo adalah Science Show. Acara Science Show ini bertujuan untuk memberikan informasi dan edukasi seputar ilmu pengetahuan tentang sains kepada anak-anak / siswa di Indonesia (Penny, 2020). Indonesia mengalami kesenjangan dalam pengetahuan Sains dan mengalami kebosanan dalam sains (Perdana,
2018). Science Show adalah salah satu bentuk media diseminasi bagi peneliti untuk mempresentasikan apa yang menjadi kepakarannya. (Penny, 2020).

Pada tahun ini, 2020, Science Show memiliki tema yaitu bagaimana cara mengenali spesies baru yang didalamnya akan dijelaskan tentang penemuan spesies apa saja yang sudah ditemukan pada tahun ini dan bagaimana cara mengidentifikasi spesies tersebut. Spesies yang akan diperkenalkan adalah spesies reptile dan amphibi yang sudah ditemukan LIPI, yaitu berupa 37 jenis baru (10 reptile dan 27 amfibi) dan 1 genus baru dalam taksonomi hewan serta bagaimana cara menemukan spesies tersebut. 
Biasanya, Science Show dilakukan secara offline atau tatap muka dengan para penontonnya. Namun, dikarena adanya pandemi Covid-19, acara science show tidak dapat diadakan secara tatap muka/offline, sehingga metode pelaksanaan acara Science Show LIPI diubah dari offline menjadi online. Untuk memudahkan kelancaran acara online tersebut, LIPI mengubah metode materi penjelasannya dari presentasi formal menjadi video motion graphic saat sesi presentasi materi. Dari hasil survey melalui kuesioner yang diadakan penulis dengan target audience pelajar SMA, hasil dari media yang paling disukai oleh pelajar SMA adalah media motion grafis karena sebagai media komunikasi video motion grapohic tidak membosankan, lebih menarik, mudah dimengerti, dan dapat diakses publik secara luas.

Berdasarkan beberapa catatan, pola pendidikan sains pada saat ini terjadi kesenjangan. banyak siswa mengalami kebosanan ketika belajar sains sehingga akhirnya menganggap pelajaran ini tidak menarik, tidak penting dan tidak relevan dengan keingintahuan dan minat pribadi mereka. Maka dari itu media video motion graphic akan dibuat menarik dan mudah dimengerti oleh siswa SMA.

Oleh karena itu, tujuan dari perancangan ini adalah merancang video motion graphic yang nantinya akan menjadi media edukasi yang diselenggarakan oleh LIPI. Perancangan video motion graphic tersebut akan berisi 2 kategori informasi yaitu bagaimana cara menemukan spesies baru dan pengenalan terhadap spesies baruyang sudah ditemukan. Dengan adanya video motion graphic ini diharapkan agar pelajar SMA dapat mengerti bagaimana cara menemukan spesies atau jenis baru ini dan mengenali spesies apa saja yang sudah ditemukan oleh para peneliti LIPI di Indonesia. Video motion graphic ini nantinya akan ditaruh di kanal Youtube LIPI kategori animasi dan akan dibagikan saat acara science show berlangsung.

\section{METODE}

Metode pengumpulan data yang digunakan penulis adalah observasi, wawancara, studi pustaka, dan kuesioner.

Observasi; metode ini dilakukan melalui memperhatikan segala hal yang telah terjadi dalam batas ruang lingkup penelitian, data harus secara objektif.

Wawancara; metode ini dilakukan secara langsung menerima informasi suatu topik melalui nara sumber/ahli di bidang yang relevan dan yang berhubungan dengan topik tersebut. Metode Ini juga berguna untuk memperkuat data penulis dan mendapatkan informasi yang tidak didapatkan di buku dan internet. 
Studi pustaka; metode ini harus dilakukan secara teliti dengan mendapatkan informasiinformasi melalui jurnal-jurnal dan studi ilmiah yang telah diteliti oleh ahli.

Kuesioner; metode ini dilakukan secara tidak tatap muka, berisi pertanyaan yang diberikan kepada target audience sebagai responden. Semua pengumpulan data tersebut tidak dipilih secara cuma-cuma.

Penulis mengambil 2 metode tersebut agar data yang didapat tepat dan memiliki akurasi yang tinggi, setelah penulis mendapatkan data tersebut, penulis menggabungkannya dan memiliki kesamaan dalam 2 metode tersebut dari data yang didapat.

Untuk metode perancangannya, penulis menggunakan metode pra produksi, produksi dan pasca produksi.

Bagan 1: Metode Perancangan

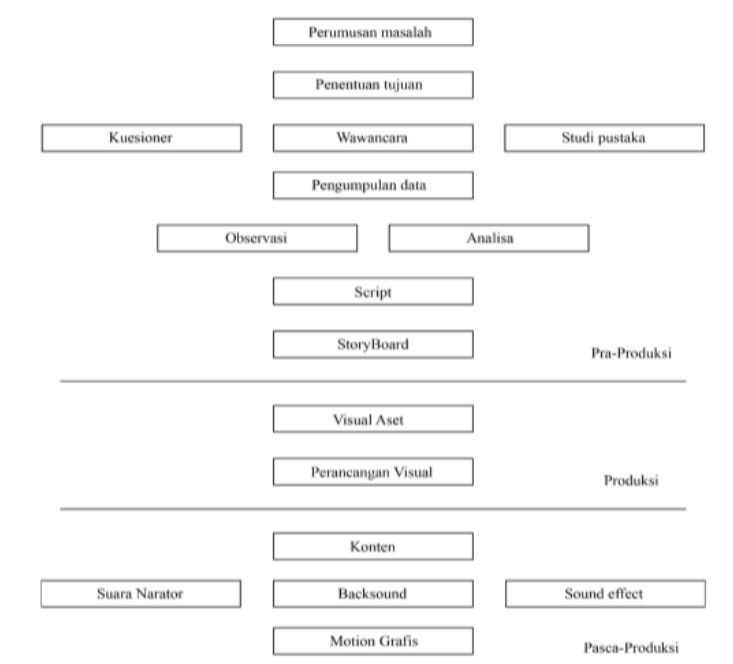

Sumber: Kingsley, 2020

\section{HASIL DAN PEMBAHASAN}

Sebelum melakukan perancangan, penulis harus menganalisis SWOT media yang akan digunakan, dan mencari solusi yang akan digunakan untuk menyelesaikan kelemahankelemahan tersebut, dan memanfaatkan kelebihan-kelebihan tersebut.

Salah satunya adalah kelebihan motion graphic memiliki visual yang menarik, dan dengan animasi dapat digerakkan seluas mungkin namun sederhana. Cocok sebagai media untuk menjelaskan hal rumit dengan penyampaian yang sederhana.

Media harus disampaikan dengan menarik, sederhana dan mudah ditangkap, karena target audience penulis adalah pelajar SMA yang memiliki psikografis yang mudah bosan akan sains.

Dari hasil riset tersebut, Penulis juga mendapatkan 88 responden untuk mengisi kuesioner, hasilnya adalah sebagai berikut;

Tabel 1: Tingkat penasaran penemuan spesies baru

\begin{tabular}{ccc}
\hline No & keterangan & Jumlah responden \\
\hline 1 & Penasaran & $83.9 \%$ \\
\hline 2 & Biasa saja & $16 \%$ \\
\hline \multicolumn{2}{c}{ Sumber: Kingsley, 2020 }
\end{tabular}

Kebanyakan reponden penasaran akan penemuan spesies baru yang ditemukan di Indonesia. Setelah melakukan kuesioner, penulis bertanya terhadap beberapa responden, pertanyaanya adalah "mengapa kalian penasaran tentang penemuan spesies 
Kingsley Valentino, Julius Andi Nugroho, Budi Darmo ; Halaman 1 - 9

baru di Indonesia"; jawabannya adalah karena dapat melihat sesuatu fauna atau flora yang belum pernah dilihat dan itu merupakan kejadian unik untuk dapat melihat sesuatu yang baru.

Tabel 2: ketertarikan terhadap video motion grafis

\begin{tabular}{ccc}
\hline No & keterangan & Jumlah responden \\
\hline 1 & Suka & $97.8 \%$ \\
\hline 2 & Tidak & $2.2 \%$ \\
\hline \multicolumn{2}{c}{ Sumber: Kingsley, 2020} &
\end{tabular}

Responden menyukai video motion graphic karena lebih mudah dipahami, menarik, fleksibel, dan seru. Rupanya video motion graphic sangat disukai oleh pelajar SMA karena alasan tersebut sesuai dengan hasil riset data kuesioner.

Tabel 3: Seberapa efektif belajar sesuatu dari motion grafis

\begin{tabular}{ccc}
\hline No & Setuju/ tidak & Jumlah responden \\
\hline 1 & Efektif & $96.6 \%$ \\
\hline 2 & Tidak efektif & $3.4 \%$ \\
\hline
\end{tabular}

Sumber: Kingsley, 2020

Faktor seberapa efektif mempelajari sesuatu dari motion graphic sangat mempengaruhi banyaknya penonton untuk video yang sudah dibuat penulis, karena jika menurut target audience media yang dibuat penulis tidak efektif maka target audience tidak akan menonton video tersebut, jika ada views nya pun akan sedikit.
Tabel 4: Style yang disukai target audience

\begin{tabular}{ccc}
\hline No & Durasi & Jumlah responden \\
\hline 1 & Simpel & $43.2 \%$ \\
\hline 2 & Modern & $27.3 \%$ \\
\hline 3 & Cute & $10.2 \%$ \\
\hline 4 & Lainnya & $19.3 \%$ \\
\hline \multicolumn{2}{l}{ Sumber: Kingsley, 2020 }
\end{tabular}

Sebanyak 43.2\% Responden menyukai tone visual yang simple, $27.3 \%$ responden yang menyukai tone visual modern, $10.2 \%$ menyukai tone visual cute dan sisanya $19.3 \%$. Karena tingkat persentase tone visual simpel tinggi, maka penulis akan menggunakan tone visual simpel, namun tone visual simpel dan modern memiliki tingkat persentase yang tinggi sudah dicampurkan, jadi penulis menggunakan 2 tone yang memiliki persentase yang tinggi yaitu $43.2 \%$; simpel dan 27.3\%; modern. Maka dari itu visual yang digunakan ada 2 yaitu simpel dan modern.

Tabel 5: tingkat persentase menonton Youtube

\begin{tabular}{ccc}
\hline No & Keterangan & Jumlah responden \\
\hline 1 & 1 Minggu $3 x$ & $14.8 \%$ \\
\hline 2 & 2 hari $1 \times 2 x$ & $64.8 \%$ \\
\hline 3 & Setiap hari & $19.3 \%$ \\
\hline 4 & jarang & $1.1 \%$ \\
\hline \multicolumn{2}{l}{ Sumber: Kingsley, 2020 }
\end{tabular}

14.8\% Responden yang menonton Youtube 1 minggu $3 x, 64.8 \%$ responden yang menonton youtube 2 hari $1 x$ atau $2 x$, responden yang menonton Youtube setiap hari adalah 19.3\% dan responden yang jarang menonton Youtube 1.1\%. Persentase diatas menunjukan bahwa Youtube adalah media yang sudah 
sangat terkenal dan sangat efektif untuk mempelajari sesuatu dari Youtube. Apalagi dimasa pandemi seperti ini, saluran video streaming semakin melonjak, salah satunya adalah media Youtube.

Dikutip dari cyberthreat.id pada tahun 2020, bahwa pengguna yang mengakses Youtube selama sebulan ialah kurang lebih 2 miliar dan angka tersebut konstan untuk beberapa bulan kedepan.

Dalam hitungan hari, orang menonton video sebanyak satu miliar jam video dan menghasilkan miliaran penayangan. Lebih dari 70 persen waktu menonton Youtube berasal dari perangkat seluler. (Youtube, 2020)

Maka dari itu media yang sudah dibuat akan dipost di Youtube karena dapat diakses seluas mungkin dan dapat diulang-ulang.

Tabel 6: Tingkat persentase ketertarikan visual

\begin{tabular}{ccc}
\hline No & keterangan & Jumlah responden \\
\hline 1 & Motion grafis & $33.3 \%$ \\
\hline 2 & $\begin{array}{c}\text { Campuran antara } \\
\text { motion grafis dan } \\
\text { footage }\end{array}$ & $66.7 \%$ \\
\hline
\end{tabular}

Sumber: Kingsley, 2020

Pada hasil table diatas ini, responden yang menyukai motion grafis full $33.3 \%$ dan campuran antara motion grafis dan footage sebesar $66.7 \%$. Maka dari itu video berupa motion graphic yang akan didukung oleh beberapa footage seperti foto spesies baru yang sudah ditemukan.
Foto spesies baru tidak mungkin di-vectorkan karena target audience tidak bisa melihat bentuk aslinya. Selain itu tujuan dari edukasi ini juga untuk menampilkan spesies apa saja yang sudah ditemukan, maka dari itu foto tidak di-vector-kan dan akan ditunjukkan sesuai foto atau footage aslinya agar lebih menarik dan nyata.

Tabel 7: Color pallete yang disukai

\begin{tabular}{ccc}
\hline No & Keterangan & Jumlah responden \\
\hline 1 & Saturation & $44.4 \%$ \\
\hline 2 & Pastel & $27.8 \%$ \\
\hline 3 & Fun & $16.7 \%$ \\
\hline 4 & Soft & $11.1 \%$ \\
\hline \multicolumn{2}{l}{ Sumber: Kingsley, 2020} &
\end{tabular}

Penulis juga menggunakan color pallete yang disukai oleh target audience, sesuai hasil riset yaitu color pallete saturation adalah $44,4 \%$, color pallete pastel adalah $27.8 \%$, color pallete fun adalah $16.7 \%$ dan color pallete soft adalah $11.1 \%$.

Dari hasil riset diatas, color pallete yang paling disukai oleh target audience pelajar SMA adalah color pallete saturation, maka dari itu penulis menggunakan color pallete saturation.

Color pallete saturation adalah sebuah warna yang memiliki tone warna yang tajam, color pallete saturation biasanya ruang lingkupnya adalah premier dan sekunder, maka dari itu color pallete saturation memiliki warna-warna yang tajam. 
Fakultas Seni Rupa dan Desain - Universitas Tarumanagara

Kingsley Valentino, Julius Andi Nugroho, Budi Darmo ; Halaman 1 - 9

Tabel 8: Typografi yang disukai

\begin{tabular}{ccc}
\hline No & Keterangan & Jumlah responden \\
\hline 1 & Roman typografi & $55.6 \%$ \\
\hline 2 & $\begin{array}{c}\text { Egyptian } \\
\text { Typografi }\end{array}$ & $11.1 \%$ \\
\hline 3 & Sans serif & $16.7 \%$ \\
\hline 4 & Serif & $16.7 \%$ \\
\hline
\end{tabular}

Sumber: Kingsley, 2020

Responden cenderung lebih menyukai roman typografi, dan urutan kedua adalah sans serif dan serif. Maka dari itu dalam video motion graphic tersebut, tulisan lebih dominan menggunakan Egyptian typografi dan jika ada beberapa visual yang bentrok dengan font Egyptian tersebut, maka alternative font lainnya adalah sans serif dan serif.

Tabel 9: Pengikut LIPI - Lembaga Ilmu Pengetahuan Indonesia

\begin{tabular}{ccc}
\hline No & Keterangan & Jumlah responden \\
\hline 1 & Tahu & $76.1 \%$ \\
\hline 2 & Tidak tahu & $23.9 \%$ \\
\hline
\end{tabular}

Sumber: Kingsley, 2020

Dari hasil riset diatas, ternyata banyak responden yang mengetahui LIPI-Lembaga Ilmu Pengetahuan Indonesia, persentase dari tabel diatas adalah yang mengetahui LIPI 76.1\% dan yang tidak mengetahui LIPI ialah $23.9 \%$.
Maka dari itu, video motion grafis ini memiliki jangkauan yang luas karena video tersebut di support oleh LIPI - Lembaga IImu Pengetahuan Indonesia yang dapat diakses oleh pengikut-pengikut LIPI yang berasal dari semua daerah, dan model client penulis adalah LIPI.

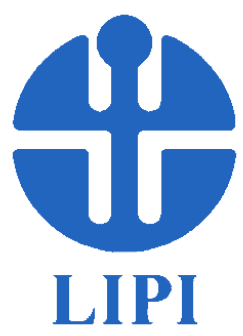

Gambar 1: Logo LIPI (sumber : LIPI, 2020)

Keputusan desain yang ditentukan penulis sesuai dengan data yang didapat yaitu motion graphic yang memiliki tone visual yang simpel dan modernisasi, dengan color pallete Saturation yang memiliki warna tajam dan menggunakan font Egyptian typografi sebagai opsi pertama dan opsi kedua sans serif atau serif.

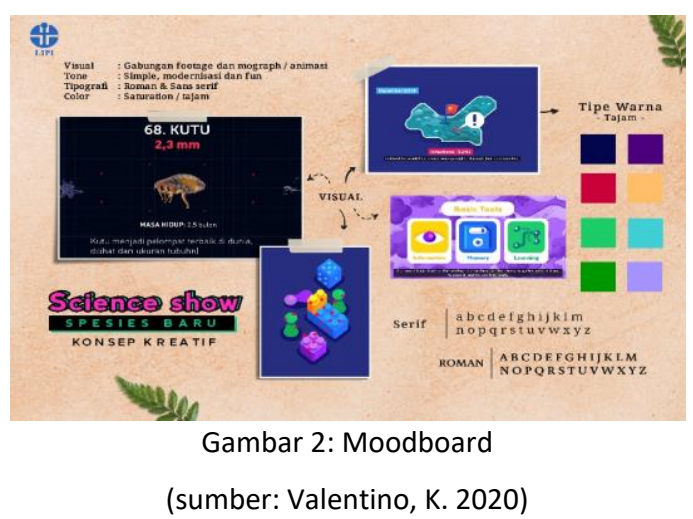


Kingsley Valentino, Julius Andi Nugroho, Budi Darmo ; Halaman 1 - 9

Video tersebut berisi karakter karena pada konsep awalnya, acara tersebut berisi sesi penjelasan tentang bagaimana cara mengenali spesies baru dan spesies apa saja yang sudah ditemukan yang dijelaskan secara presentasi formal, karena diubah menjadi online menggunakan video motion graphic, maka video motion graphic tersebut tetap memiliki karakter yang akan menjelaskan tentang materi tersebut.

Karakter dalam video tersebut adalah Dr. Amir Hamidy, selaku peneliti herpetology dari LIPI yang memimpin tim untuk menemukan spesies tersebut dari berbagai daerah di Indonesia. Karakter Dr. Amir Hamidy tersebut berkulit coklat dan berambut hitam, memiliki kumis dan jenggot yang tipis, dan terlihat seperti orang Indonesia.

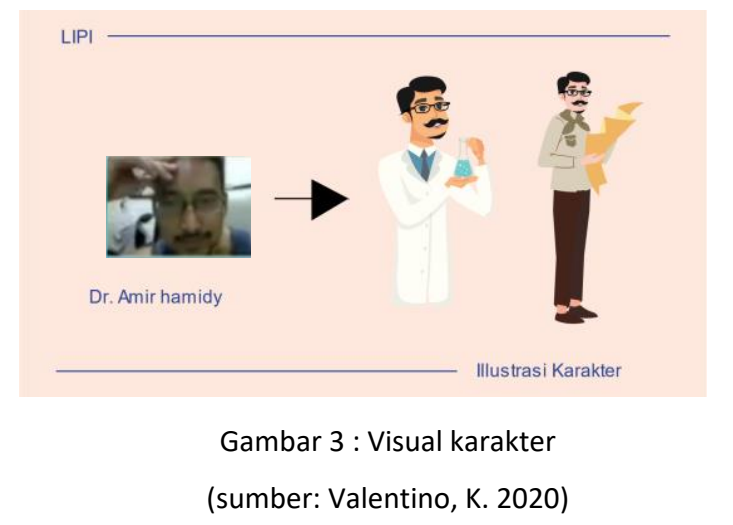

Tidak hanya tokoh utama, penulis juga membuat konsep kreatif untuk background dan elemen visual dalam video tersebut. Untuk background, penulis membuat background tersebut sesuai dengan background aslinya, background memiliki referensi yaitu ruangan dan bentuk Gedung LIPI dan di-vector-kan.

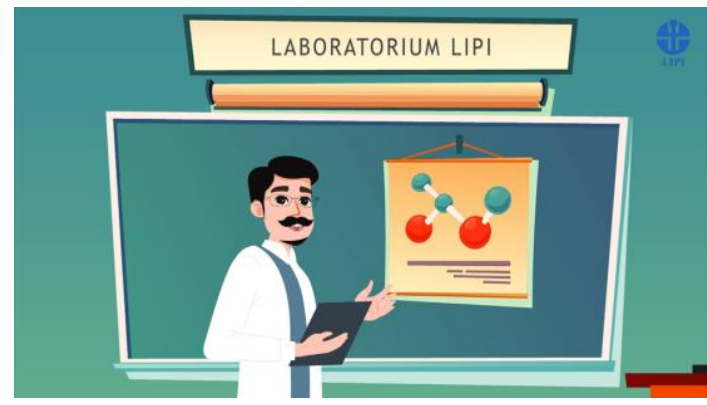

Gambar 4: Background Laboratorium LIPI

(sumber:Valentino,K. 2020)

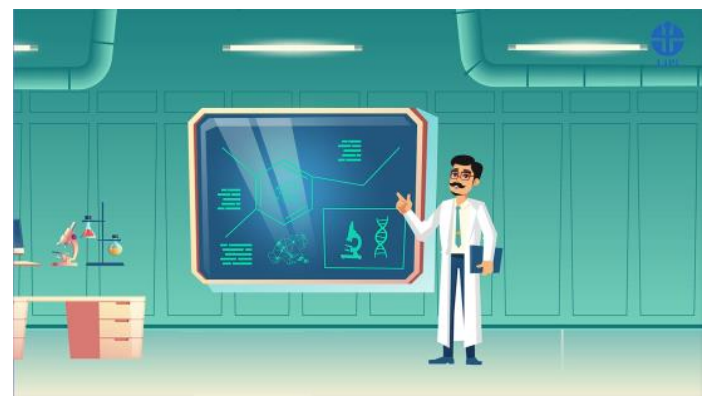

Gambar 5: Background ruangan herpetologi LIPI (sumber:Valentino,K. 2020)

Elemen visual yang digunakan juga bukan sekedar tambahan, tetapi elemen visual tersebut dibuat sesuai dengan konsep sains untuk mendukung karakter dan background yang sudah di vector agar memiliki unity dan menarik.

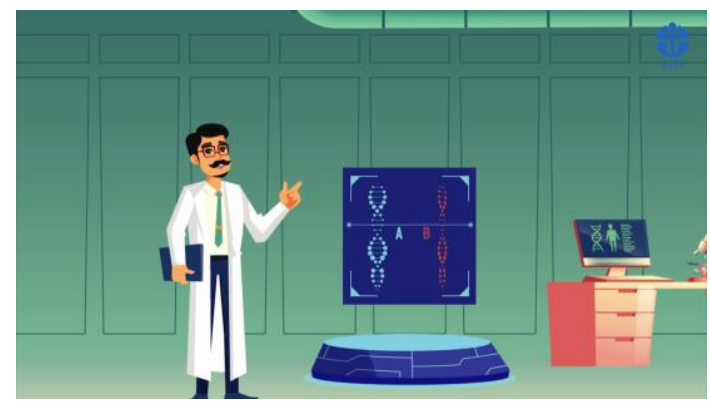

Gambar 6: Elemen SAINS (sumber: Valentino,K. 2020) 
Kingsley Valentino, Julius Andi Nugroho, Budi Darmo ; Halaman 1 - 9

Maka dari itu kesimpulan dari konsep kreatif tersebut ialah motion graphic yang dirancang berupa video informatif, Pada tema motion graphic tersebut, tone yang dipakai adalah simple dan modern, memiliki karakter, sound effect dan backsound.

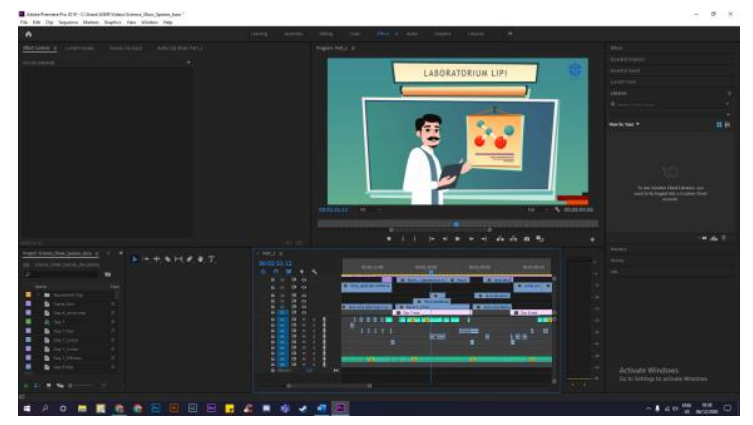

Gambar 7: Editing sound

(sumber:Valentino,K. 2020)

Motion graphic menggunakan karakter sebagai tokoh utamanya, bernama Dr. Amir Hamidy adalah peneliti LIPI yang berasal dari Indonesia asli, dalam video motion grafis tersebut Dr. Amir Hamidy menjelaskan tentang spesies apa saja yang baru ditemukan di Indonesia dan bagaimana cara menemukan spesies tersebut.

Dalam video tersebut visual akan dibuat menyerupai elemen LIPI seperti karakter Dr. Amir Hamidy selaku peneliti dari LIPI yang di illustrasikan sesuai dengan referensi foto Dr. Amir Hamidy tersebut, Illustrasi Gedung lipi sesuai dengan referensi foto Gedung LIPI pada aslinya, Spesies yang ditemukan berupa foto, agar penonton dapat melihat bentuk aslinya.

Konsep yang simpel dan sederhana, backsound yang digunakan adalah musik yang memiliki tone asik agar penonton merasa terpacu oleh tone musik tersebut dan didukung oleh pergerakan dalam visual tersebut, dan tidak semua pergerakan diisi dengan sound effect, karena dapat membuat penonton menjadi pusing mendengar suara yang berulang-ulang, dan typeface yang digunakan adalah sans serif dan roman typografi.

\section{SIMPULAN}

Karena acara science show tidak bisa diadakan secara offline maka membutuhkan video motion grafis sebagai media informatif nya untuk menjelaskan sesi materi tersebut.

Oleh karena itu, penulis merancang video motion graphic yang memiliki tone visual sesuai dengan data yang didapatkan oleh target yang berisi bagaimana cara mengenali spesies baru dan spesies apa saja yang sudah ditemukan dengan menarik.

Hasil perancangan video motion graphic tersebut berdurasi 5-6 menit, memiliki resolusi Full HD yaitu 1920 x 1080 px, yang akan dipost di kanal Youtube LIPI - Lembaga IImu Pengetahuan Indonesia dengan visual yang menarik dan tidak membosankan.

Kelebihan penelitian ini adalah mengedukasi tentang sains, dan menyadarkan bahwa pengetahuan tentang Sains ternyata tidak membosankan, hanya saja cara 
Kingsley Valentino, Julius Andi Nugroho, Budi Darmo ; Halaman 1 - 9

penyampaiannya yang tidak menarik, maka dari itu penulis membuat video motion graphic agar metode penjelasan dapat diminati oleh pelajar SMA.

Kekurangan penelitian ini adalah waktu yang digunakan untuk membuat video tersebut memiliki jangka waktu yang lama yaitu 1-2 bulan.

\section{UCAPAN TERIMA KASIH}

Penulis mengucapkan terima kasih yang sebesar-besarnya kepada Penny Sylvania Putri, M.Sn. dari LIPI karena telah bersedia meluangkan waktunya untuk menjawab pertanyaan-pertanyaan penulis, serta membantu penulis untuk mendapatkan datadata secara jelas dan lengkap.

Tidak lupa juga untuk pihak-pihak yang telah menyediakan jurnal dan studi ilmiah yang mampu memperkuat kredibilitas penulis, serta memberikan fakta dan infromasi baru yang belum diketahui penulis sebelumnya. Terima kasih juga kepada responden kuesioner yang telah bersedia meluangkan waktu mereka untuk membantu penulis dalam pengumpulan data Tugas Akhir.

\section{DAFTAR PUSTAKA}

Nugroho, A. (2020, September 17). 15 Tahun Berdiri, Ini Sejumlah Fakta tentang YouTube. Cyberthreat.Id. https://cyberthreat.id/read/8480/15-

Tahun-Berdiri-Ini-Sejumlah-Fakta-

tentang-YouTube

Cohen, D. (2020, December 14). Baby Boomers Became YouTube Creators in a Big Way in

2020.https://www.adweek.com/digita I/baby-boomers-became-youtubecreators-in-a-big-way-in-2020/

Prima Perdana, P. (2019, December 5). Peringkat Indonesia di PISA Jeblok, Komisi X Minta Pemerintah Bikin Langkah Terobosan. KOMPAS.Com. https://regional.kompas.com/read/20 19/12/05/07585081/peringkatindonesia-di-pisa-jeblok-komisi-xminta-pemerintah-bikin-langkah

Permana, D. (2020, November 22). Kuantitatif dan Kualitatif: Pengertian, Metode dan Perbedaan.

Tedas. https://tedas.id/pendidikan/kuliah/ku antitatif-dan-kualitatif/ 